\title{
Application of Grey Theory in the Construction of Impact Criteria and Prediction Model of Players' Salary Structure
}

\author{
Chung-Chu Chuang, ${ }^{1}$ Tien-Tze Chen, ${ }^{2}$ and Chih-Cheng Chen $\mathbb{D}^{1,2}$ \\ ${ }^{1}$ Department of Management Sciences, Tamkang University, New Taipei City, Taiwan \\ ${ }^{2}$ Department of Sport Management, Aletheia University, New Taipei City, Taiwan \\ Correspondence should be addressed to Chih-Cheng Chen; au1692@au.edu.tw
}

Received 22 September 2017; Revised 10 January 2018; Accepted 22 January 2018; Published 25 February 2018

Academic Editor: Emilio Jiménez Macías

Copyright (c) 2018 Chung-Chu Chuang et al. This is an open access article distributed under the Creative Commons Attribution License, which permits unrestricted use, distribution, and reproduction in any medium, provided the original work is properly cited.

\begin{abstract}
Salaries of professional players are usually determined prior to the execution of the responsibilities assigned by the organizations and are often based on the expected future performance of these players as derived from their past achievement. The study first identifies criteria that would affect players' salaries through literature reviews and then utilizes grey relational analysis (GRA) and grey prediction model to calculate weights of salary impact criteria, players' annual performance index, and salary prediction for the coming year. The performance data of players from the Chinese Professional Baseball League (CPBL) are used in this study. The results are as follows: (i) CPBL teams do refer to players' past performance records and future performance prediction when deciding on their salaries and (ii) future performance prediction must be made using at least a 3-year data set. The proposed prediction model is able to effectively provide relevant and useful information to the CPBL teams' management during players' salary adjustment.
\end{abstract}

\section{Introduction}

1.1. Problem Description. Regardless of the types of organizations, in order to reach their goals and objectives, organizations need their employees to work hard towards achieving them. One of the effective tools organizations can use to motivate and compensate their employees is salary. Salary is a form of remuneration used by organizations in exchange for their employees to work towards organizational goals. In terms of organizational effectiveness, salaries have been known to influence important organizational indicators such as recruitment and retention of staff, staff performance incentive, staff skill development promotion, development of organizational culture and structures, operating costs, and job satisfaction [1]. As described in expectancy theory, employees will have the motivation to perform once they believe the organization will provide the desired rewards contingent on their performance [2]. Thus it is no different for teams in professional sports leagues where generous salaries are offered to attract, retain, and/or motivate players. Recently a study was conducted to analyze the values of these professional sports firms using data collected between 2004 and 2011 from four major US sports leagues (Major League Baseball, National Basketball Association, National Football League, and National Hockey League) and European professional football leagues, provided by Forbes magazine. Scelles et al. [3] found that only the sports firms' past performance records alone can significantly and positively affect the firms' values in these leagues. Many scholars have also pointed out that the performances of professional sports teams have a positive correlation with the patrons/fans' willingness to watch the games live at the stadiums $[4,5]$. In summary, the performance of a professional sports team will have a positive effect on the monetary value of the team and the willingness of its patrons/fans to watch the game live at the stadium. Thus every manager and owner of these professional sports teams would do their utmost to improve and enhance the strength of their teams.

Salary is an effective tool not just in attracting new highperforming players but also in retaining and motivating existing players. These are done in the hope of strengthening the teams' performance, attracting patrons to their games, 
and increasing the teams' values as mentioned earlier. Hence it is imperative to research and understand salary-related issues of professional sportspersons. Intrinsic and extrinsic rewards are the two types of compensations an organization can utilize. Intrinsic rewards include intangible rewards such as public recognition, job satisfaction, professional growth, status, and image, while extrinsic rewards comprise tangible and visible rewards such as remunerations, promotions, bonuses, and incentives. For sports researchers the correlation between player productivity, compensation, and team winnings is clear [6]. With large public support and economy of scale, the Chinese Professional Baseball League (CPBL) is the most prominent professional sports organization in Taiwan; thus this study focuses on players within the CPBL. Based on expectancy theory, salary compensation is one of the main motivational incentives for player productivity and player-related information in the CBPL can be easily obtained; this study will analyze and explore salary issues of these CPBL players.

Salary has always been a point of contention in industrial relations. Employees hope to get higher salaries while employers want to minimize labor cost as much as possible in order to maximize their profits. At the end of each season, professional players will enter into tense salary negotiations with their existing teams or new interested parties. During these negotiations, players want to be recognized and remunerated accordingly for the year's hard work. Unfortunately, the negotiation processes do not usually turn out as expected, which may cause players to feel depressed and/or to decide to leave the team. Nonetheless, their performance will no doubt be affected in the coming season. Previous studies on professional sports (either professional baseball or professional basketball) have shown that team managements tend to rely on simple evaluation methods or make decision subjectively when it comes to the determination of player salary [6-9]. In addition, salaries of professional players have always been shown to have a significant positive relationship with their performance during competition, and yet decisionmakers undervalue important performance factors that are difficult to convincingly connect to the outcomes due to the complexities of the decision-making process [10]. Many studies have found that decision-makers tend to only focus on scoring as the singular performance indicator when deciding how much to pay their players $[7,10]$.

In summary, decision-makers are prone to use simple intuitive judgment or their own personal preferences while deciding their players' salaries. Thus issues related to the salaries of professional sportspersons continue to be of interest to both researchers and the general public. Most of the previous studies on player salary focused on the relationship between team performance and salary [11-13] or players' performance $[7,10,14,15]$. Only a few studies had looked into salary impact criteria for players and/or teams [16]. Hence this study hopes to investigate salary impact criteria of professional players by first finding possible salary impact criteria of professional baseball players through literature review, then utilizing quantitative statistical information obtained through the official CPBL website (http://www.cpbl.com.tw), to calculate the criteria's weights using grey relational analysis
(GRA), and finally predicting player salaries using grey prediction model.

Since both employers and employees view salary as an integral part of their contract, more so in the world of professional sports, there is no lack of negotiation drama and suspense after the end of every competitive season. Most articles on the topic of salary in professional sports generally analyze player salaries and the relationship between salary and performance using three types of salary systems, namely, job-based, skill-based, and performance-based salary systems [7, 10-14]. However, salaries of professional players are usually determined prior to the execution of the responsibilities assigned by their teams and are often based on the expected future performance of these players as derived from their past achievement [6]. Based on the above argument, team management should refer to not only the players' performance from previous seasons but also possible future performances while deciding the salaries of their professional players. As the concept of division of labor within manufacturing is often overlooked in the sporting world, player performance evaluation should be a multicriteria decision-making (MCDM) problem. Outstanding basketball players are required to dribble, shoot, rebound, pass, and defend, while invaluable baseball players are those who can hit for average, hit for power, run, field, and throw. In other words, good professional basketball and baseball players do not quite conform to the concept of professional division of labor [10]. Thus teams should not evaluate their players using one single performance criterion $[7,10]$ while determining their players' salaries. Most of the previous researches on salaries of professional players and/or teams employed regression analysis $[7,10-14]$ to explore the relationship between performance and salary. This meant that these studies only take into account players' past performance records and did not consider what the teams want from these players in their upcoming games/seasons. In summary, determining players' salaries is a MCDM problem, and both past performance records and future performance prediction should be taken into consideration while determining players' salaries. Therefore in order to solve the problem above, this study uses GRA to assist the CPBL teams in constructing an effective performance evaluation model. As a nonfunctional sequence model, GRA is a part of grey system theory, suitable for solving problems with complicated interrelationships between multiple factors and variables. Also, GRA method is easy to learn and does not require huge amount of data; data used do not need to be in normal distribution and do not produce results that will be in conflict with other quantitative analyses. It has been proven to be useful for dealing with poor, incomplete, and uncertain information. These advantages have enabled GRA to be widely applied in various fields to solve uncertainty problems under discrete data and incomplete information. Thus this study hopes to utilize GRA in determining the weights of salary impact criteria and annual performance indexes for players in the CPBL.

Professional sports usually employ data mining or stochastic modeling for prediction results [17-20], while other fields often utilize regression analysis. These methods 
require a large amount of data to provide good prediction. In the CPBL, the number of available data for each player varies. Yet even for senior players there are only a dozen or so annual/quarterly performance indexes available per player for analysis. Thus the above-mentioned method is not suitable. Instead, to overcome the issue of limited data in the CPBL, this study will employ the grey prediction method, a method that has been used in fields of retailing $[21,22]$, electronics [23], hospitality and transportation [24$26]$, power systems $[27,28]$, and energy [29, 30], to derive the performance index of the players for the new season.

In summary, this study aims to solve the issue of performance evaluation for professional sportsperson as a multicriteria decision-making problem. Since the available sample data is small, this study will first search through past literature to seek out the salary impact criteria of players in the CPBL and then employ GRA to calculate the weights of these criteria and the various performance indexes for players. Next, grey prediction method will be used to find the performance index of the new season for players in the league teams. From the results obtained, this study tries to understand how current and future performance indexes will affect the current annual salary of these players. By providing the correct analysis and context, this study hopes to provide empirical references to the management and/or coaches when they make decisions regarding players' salaries.

1.2. Research Purpose. In order to effectively find and construct criteria that would affect the salary structure of players in the CPBL and thus the proposed prediction model, this study aims to achieve the following:

(a) Figuring out the weights for criteria that will affect the salaries of players in the CPBL

(b) Empirical analysis: salary prediction of players in the CBPL.

The following sections are research methods, results, and discussion.

\section{Research Methods}

The objective of this study is to construct a salary prediction model for players in the CPBL by utilizing various annual performance data between 2011 and 2014. This study first identifies criteria that would affect players' salaries through literature reviews and then utilizes GRA to calculate the weights of these criteria and the various annual/quarter performance indexes for players. Next, grey prediction method will be used to derive the performance index of the players for the new season and GRA will be used once again to predict the salary for players in the 2015 season.

2.1. Research Framework. First, this study identifies criteria that would affect players' salaries through literature reviews and then utilizes GRA and grey prediction analysis to calculate weights of salary impact criteria, annual performance index of players, and predictive index of players' salary for the coming year. The performance indexes of players from the
CPBL between 2011 and 2014 are used. Figure 1 illustrates the research framework.

2.2. Salary Impact Criteria in Professional Baseball. A quick look at studies on professional baseball players and their salaries will show that researchers have found a considerable number of factors affecting wages of these players. Silver slugger point (SSP), run (R), total bases on safe hits (TB), run batted in (RBI), on base percentage (OBP), and slugging percentage (SLG) are the six common performance criteria used to evaluate fielders $[15,31]$, while pitchers are evaluated on five different performance criteria, namely, complete game shut-out (SHO), strike-out per nine innings (K/9), walks plus hits per inning pitched (WHIP), earned run average (ERA), and innings pitched (IP). Based on the above, this study utilizes quantitative indicators to evaluate the salary structure of professional baseball players.

\subsection{Data Processing}

2.3.1. Grey Relational Analysis. As the problem of salaries for professional baseball players is one of multicriteria, it should be represented in a comprehensive manner. GRA, a part of grey system theory, is one of the very popular methods to analyze various relationships among the discrete data sets and make decisions in multiple criteria situations. Thus, this study uses GRA to calculate the weights of these salary impact criteria, annual performance indexes, and salary prediction for the next year. Steps for GRA are as follows.

Step 1 (reference and comparison sequences generation). Find the reference sequence $x_{0}$ and comparison sequences $x_{1}, x_{2}, \ldots, x_{n}$ from the original matrix $A$. Reference sequence in this study refers to the set of ideal goal values for each key criterion, while comparison sequence is the performance index for each position on each team.

Step 2 (original matrixes normalization). There are three different methods of normalizing the sequences, namely, the-larger-the-better, the-smaller-the-better, and the-morenominal-the-better methods. In this study, only the first two methods are used and they are as follows.

The-larger-the-better method indicates that the larger target value is better. The calculation is as follows:

$$
X_{i j}^{*}=\frac{x_{i j}-\min _{i} x_{i j}}{\max _{i} x_{i j}-\min _{i} x_{i j}},
$$

where $\max _{i} x_{i j}$ is the largest value in index $j$ and $\min _{i} x_{i j}$ is the smallest value in index $j$.

The-smaller-the-better method indicates that the smaller target value is better. Its calculation is

$$
X_{i j}^{*}=\frac{\max _{i} x_{i j}-x_{i j}}{\max _{i} x_{i j}-\min _{i} x_{i j}},
$$

where $\max _{i} x_{i j}$ is the largest value in index $j$ and $\min _{i} x_{i j}$ is the smallest value in index $j$. 


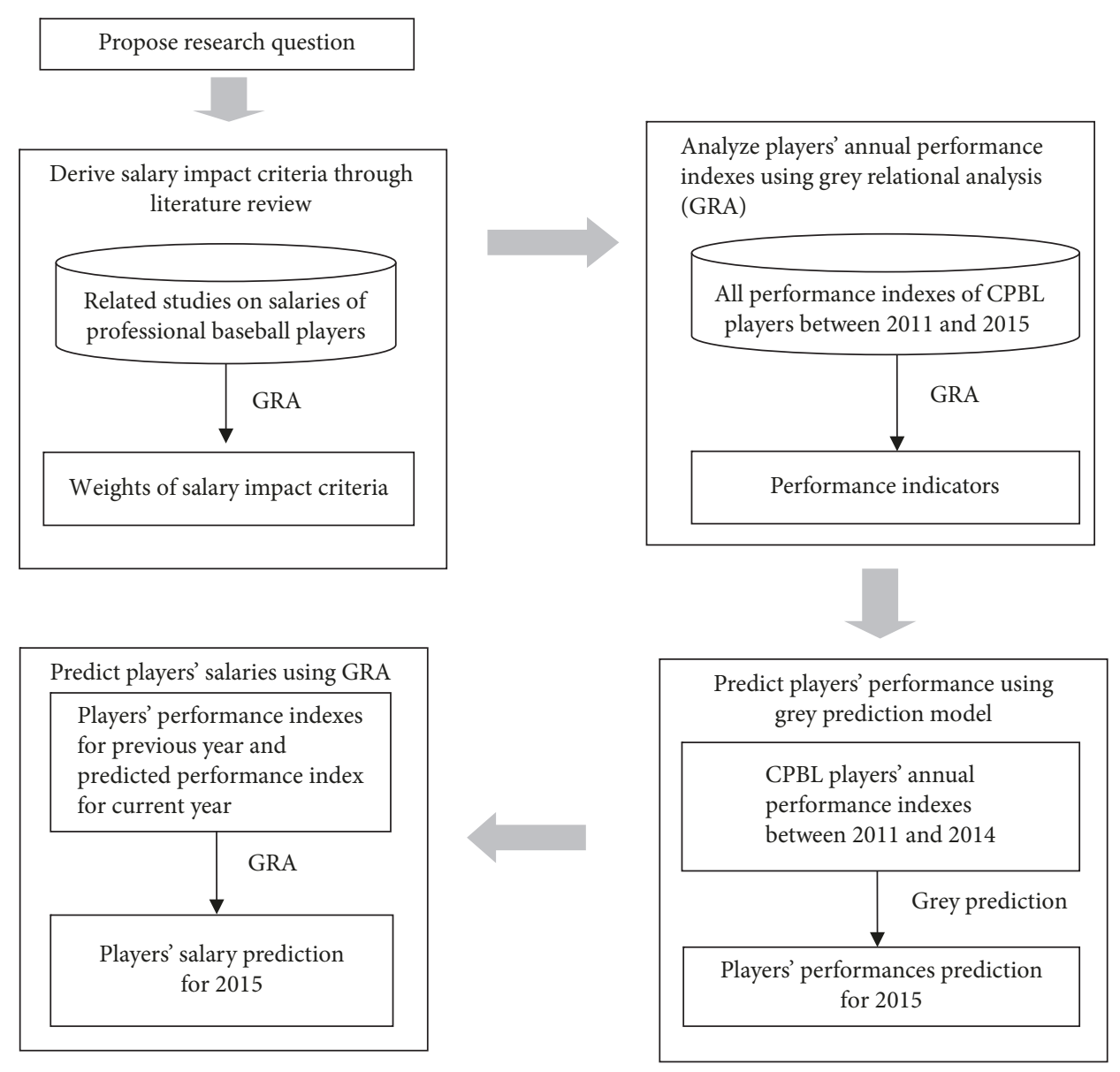

FIGURE 1: Research framework.

Step 3 (grey relational distance $\Delta_{0 i}$ calculation). $\Delta_{i j}$ measures the distance between each comparison and reference sequences after normalization and is calculated as follows:

$$
\Delta_{i j}=\left|x_{0 j}^{*}-x_{i j}^{*}\right|
$$

where $x_{0 j}^{*}$ is the normalized reference sequence value and $x_{i j}^{*}$ is the normalized comparison sequence value.

Step 4 (grey relational coefficient $\gamma_{0 i j}$ calculation). The following shows the calculation for $\gamma_{0 i j}$ :

$$
\gamma_{0 i j}=\frac{\Delta \min +\xi \Delta \max }{\Delta_{i j}+\xi \Delta \max },
$$

where $\Delta \max =\max _{\forall i} \max _{\forall i} \Delta_{i j}, \Delta \min =\min _{\forall i} \min _{\forall i} \Delta_{i j}$, and $\xi \in[0,1]$.

$\xi$ is the distinguishing coefficient whose purpose is to expand or compress the range of the grey relational coefficient. Generally 0.5 is taken as a benchmark [32].

Step 5 (grey relational grade $\Gamma_{0 i}$ calculation). For each scenario, multiply the grey relational coefficient with the weights of each criterion and the weighted average obtained is the grey relational grade that indicates the degree of similarity between the comparison and reference sequence. The higher grey relational grade is better.

$$
\Gamma_{0 i}=\sum_{j=1}^{n} w_{j} \times \gamma_{0 i j},
$$

where $w_{j}$ is the weight and $\sum_{j=1}^{n} w_{j}=1$ denotes the normalized weight.

This study uses regression analysis to derive the normalized weights for each key criterion.

Step 6 (grey relational sequencing). Weights of salary impact criteria are ranked by grey relational grade. The greater grey relational grade $\Gamma_{0 i}$ indicates its greater weight. Further, in terms of player performance, the greater grey relational grade $\Gamma_{0 i}$ indicates the better player performance. Then, in salary forecasting, player performance index from predicted performance index for current year minus performance index from previous year is used. If the value obtained after subtracting $\Gamma_{0 i}$ of previous year from the predicted $\Gamma_{0 i}$ one is positive, this shows a salary increase for the player. If the value is negative, the player suffered a salary cut.

2.3.2. Grey Prediction Model. It is known that salaries of professional players are usually determined prior to the 
execution of their team-assigned responsibilities and are often based on the future performance prediction of these players. The grey prediction model is to establish a grey model extending from past information to the future based upon the past and present known or undeterminate information. As this type of salary information is incomplete (partially known, partially unknown) and the number of player performance indexes is small, this study decides to employ grey prediction model to make its prediction. Steps for grey prediction $\operatorname{GM}(1,1)$ model are as follows $[22,24]$.

Step 1 (accumulated generating operation (AGO)). Let $X^{(0)}$ represent nonnegative initial data series; thus the equation is

$$
X^{(0)}(k)=\left(X^{0}(1), X^{0}(2), \ldots, X^{0}(n)\right), \quad n \geq 4
$$

and the original grey differential equation of $\operatorname{GM}(1,1)$ model can be described as

$$
X^{(0)}(k)+a Z^{(1)}(k)=b, \quad k \in\{2,3, \ldots, n\} .
$$

Since (7) is not a true differential equation, the general differential equation used in grey prediction is

$$
\frac{d x^{(1)}}{d t}+a x^{(1)}=b,
$$

where $a$ is the developed coefficient and $b$ is the grey controlled variable of the prediction model. Thus the AGO is represented as

$$
\begin{array}{r}
X^{(1)}(k)=\mathrm{AGO} \times X^{0}(k)=\sum_{i=1}^{k} X^{(0)}(i), \\
\quad k \in\{1,2,3, \ldots, n\} .
\end{array}
$$

Step 2 (applying mean generating operation). In $\operatorname{GM}(1,1)$ model, the equation to derive $Z^{(1)}(k)$ is denoted by

$$
\begin{aligned}
Z^{(1)}(k)=\frac{1}{2} \times\left\{X^{(1)}(k)+X^{(1)}(k-1)\right\} & \\
k & \in\{2,3, \ldots, n\} .
\end{aligned}
$$

Step 3. Using the ordinal least square (OLS) method, the grey parameter matrix can be found as follows:

$$
\widehat{A}=\left[\begin{array}{l}
a \\
b
\end{array}\right]=\left(B^{T} B\right)^{-1} B^{T} Y_{N} .
$$

Let

$$
B=\left[\begin{array}{ccc}
-Z^{(1)} & (2) & 1 \\
-Z^{(1)} & (3) & 1 \\
-Z^{(1)} & (4) 1 \\
\vdots & \\
-Z^{(1)} & (n) 1
\end{array}\right],
$$

where

$$
Y_{n}=\left[X^{(0)}(2), X^{(0)}(3), \ldots, X^{(0)}(n)\right]^{T}
$$

The derived differential equation of AGO is denoted as

$$
X^{(1)}(n+p)=\left(X^{0}(1)-\frac{b}{a}\right) e^{-a(n+p-1)}+\frac{b}{a} .
$$

Step 4 (inverse accumulated generating operation (IAGO)). IAGO is as follows:

$$
\begin{aligned}
\widehat{X}^{(0)} & =\widehat{X}^{(1)}(k)-\widehat{X}^{(1)}(k-1) k \\
\widehat{X}^{(0)} & =\widehat{X}^{(1)}(n+p)-\widehat{X}^{(1)}(n+p-1) \\
& =\left(X^{(0)}-\frac{b}{a}\right) \times\left(e^{-a(n+p-1)}\left(1-e^{a}\right)\right) .
\end{aligned}
$$

2.3.3. Mean Absolute Percentage Error (MAPE). In order to find the accuracy of the salary prediction model proposed in this study, mean absolute percentage error is used to calculate the error value, as shown in (16) [33]:

$$
\text { MAPE }=\frac{\sum\left(\mid \text { actual }_{t}-\text { predict }_{t} \mid / \text { actual }_{t}\right) \times 100}{n} .
$$

2.3.4. Pearson Relational Analysis. To assess whether the CPBL teams are paying their players reasonably, this study uses Pearson Relational Analysis to evaluate the relationship between players' actual performance, predicted performance, and their salaries.

2.4. Data Source and Limitation. Quantitative statistical information on player salaries, salary impact criteria, and player lists are all obtained through official professional baseball magazines and the official CPBL website (http:// www.cpbl.com.tw) $[34,35]$. The salaries and player list were adopted from the professional baseball magazines, which were announced before the baseball season began. Quantitative data affecting salary criteria were obtained from the players' information announced on the official website of the CPBL. To obtain the weights for the salary impact criteria, this study adopted the 2015 player list provided by the CPBL official website, as well as the quantitative data of the annual salary of those players and the evaluation criteria from 2011 to 2014. In 2011, the team had a total of 60 players, comprising 40 fielders and 20 pitchers; in 2012, the team had a total of 83 players, comprising 54 fielders and 29 pitchers; in 2013, the team had a total of 99 players, comprising 62 fielders and 37 pitchers; and in 2014, the team had a total of 131 players, comprising 75 fielders and 56 pitchers. A total of 373 pieces of data were acquired from the 4 -year duration. The data included the criteria used to evaluate fielders' salary, namely, SSP, runs, total bases, runs batted in, on base percentages, and slugging percentages, comprising 231 pieces of data. The criteria used to evaluate pitchers' salary, namely, shutouts, strikeouts per nine innings pitched, walks hits per inning pitched, earned run averages, and 
innings pitched, were also obtained, comprising 142 pieces of data. The data were entered into Excel, and the weight of each criterion (including the previous and current seasons) affecting salary was calculated by following the grey relational analysis steps (please refer to http:/ccchen.epage.au.edu.tw/ files/13-1101-62643.php?Lang=zh-tw); subsequently, the annual player performance indexes were calculated. Next, us ing the grey prediction model (please refer to http://ccchen .epage.au.edu.tw/files/13-1101-62643.php?Lang=zh-tw), the aforementioned player performance indexes were employed to calculate the 2015 player performance indexes. Foreign players with frequent transfers and players who had played less than one year in the league have been excluded from this study. Annual performance index for players who had played two or more years in the league will be used to predict their performance index for the new season year. Salary data used in this study will be the monthly salary of these CPBL players.

\section{Results}

3.1. Evaluating Weightage of Criteria Affecting Player Salaries in the $C P B L$. As players within the professional baseball league are categorized as fielders and pitchers, they each have a different set of performance evaluation criteria. This study uses six criteria to assess the performance of fielders, RBI, R, TB, OBP, SLG, and SSP. SHO, K/9, WHIP, ERA, and IP are the five performance criteria used to evaluate pitchers. In order to find out how the performance of these CPBL players affects the weights of these salary impact criteria, this study treats the previous and current seasons as comparative series while treating individual players' salaries for these seasons as reference series. By using GRA, weights of these salary impact criteria can be calculated. Results of the analysis are shown in Table 1 (for fielder) and Table 2 (for pitchers).

Table 1 shows that fielders' performance in previous and current seasons has similar effect on the criteria weights, with values of 0.493 and 0.507 , respectively. Among them, RBI has the highest weight of 0.183 (previous season at 0.091 and current season at 0.092 ), followed by TB with a weightage of 0.176 ( 0.087 and 0.089 for previous and current season, resp.). $\mathrm{R}$ at 0.175 (0.087 and 0.088 , resp.), SSP at 0.172 (0.083 and 0.089 , resp.), OBP at 0.155 (0.075 and 0.080, resp.), and SLG at $0.140(0.070$ and 0.070 , resp.) made up the rest of the criteria weights.

Likewise, how CPBL pitchers perform in previous and current seasons was also found to affect criteria weights similarly, as shown in Table 2. Criteria weights for previous and current seasons are 0.493 and 0.507 , respectively. SHO carries the highest weights among the five performance criteria at 0.256 (previous season at 0.127 and current season at 0.129$)$, followed by $\mathrm{K} / 9$ at 0.241 (0.118 and 0.123 , resp.), inning pitched (IP) at 0.226 (0.110 and 0.116 , resp.), WHIP at 0.143 (0.071 and 0.072, resp.), and ERA at 0.134 (0.067 and 0.067 , resp.).

3.2. Empirical Analysis: Salary Prediction for Players in the $C P B L$. This study first utilizes GRA to calculate the weights of criteria affecting the salaries of CPBL players. Next, grey prediction model is used to derive possible performance index of both fielders and pitchers for 2015 season and subsequently calculate the difference between actual performance index and predicted performance index for all players in 2015. In order to decide the accuracy of the salary prediction model proposed, this study then uses MAPE to calculate the error value. Furthermore, this study also utilizes relevant data to calculate the rate of salary adjustment for players in 2014 and 2015 and then calculate the gap between the predicted and actual performance index for 2015 and annual performance index for 2014. These figures will help determine whether the salary adjustments made by the teams in CBPL are reasonable.

As predicting what may happen in the future is a herculean task, there is a need to evaluate the accuracy and suitability of the prediction model proposed in this study. According to [36] definition of the MAPE value, highly accurate forecasts are associated with the model if the MAPE is less than or equal to $10 \%$; good forecasts for MAPE are between 10 and 20\%; reasonable forecasting for MAPE is of $20-50 \%$; and inaccurate forecasting for MAPE is more than $50 \%[33]$.

From the figures listed in Table 3, the prediction model proposed in this study can be used to forecast overall performance of all players as the error value is $35.1 \%$, which is within the reasonable forecasting range. Looking closer, the error value of the model with three and four years' worth of performance data is $15.2 \%$ and $18.2 \%$, respectively. Both values indicated that the suggested model has good forecasting abilities for both data sets. However, the prediction model proposed is inaccurate when using a two-year data set since at $141.3 \%$ the error value greatly exceeded the $50 \%$ threshold. For players in different positions, the error value for overall performance of pitchers is $46.5 \%$, while for fielders it is $28.2 \%$. This meant that generally the proposed model has reasonable forecasting abilities for pitchers and fielders. In terms of data ranges, the model has good forecasting abilities with three and four years' worth of data as the error values range between $12.5 \%$ and $20.2 \%$. Again, the model is unable to provide accurate prediction for either pitchers or fielders using a two-year data set with the corresponding error values being $161.0 \%$ and $124.0 \%$.

To determine whether or not the salaries of players in the CBPL are adjusted based on their actual performances, this study first uses relevant data to calculate the changes in the predicted and actual performance index for 2015 and annual performance index for 2014. As shown in Table 4, the rate of salary adjustment for players in the CBPL for the 2015 season is 0.119 , while the actual performance gap between 2014 and 2015 averages at -0.062 and the predicted performance gap for the same time period averages at 0.101 . This study then utilizes Pearson Relational Analysis to understand the relationship between the rate of salary adjustment and the differences in players' performance index for 2015. Results showed that rate of salary adjustment is positively correlated with the players' predicted performance gap but is negatively correlated with the players' actual performance gap. 
TABLE 1: Results of GRA and criteria weights of CPBL fielders' performance.

\begin{tabular}{ccccc}
\hline Reference series & Comparative series & Criteria weights (previous season) & Criteria weights (current season) & Total weights \\
\hline \multirow{6}{*}{ Salary } & RBI & .091 & .092 & .183 \\
R & TB & .087 & .088 & .175 \\
& OBP & .087 & .089 & .176 \\
SLG & .075 & .080 & .155 \\
SSP & .070 & .070 & .140 \\
& Total weights & .083 & .089 & .172 \\
& & .493 & .507 & 1.000 \\
\hline
\end{tabular}

TABLE 2: Results of GRA and criteria weights of CPBL pitchers' performance.

\begin{tabular}{lcccc}
\hline Reference series & Comparative series & Criteria weights (previous season) & Criteria weights (current season) & Total weights \\
\hline \multirow{6}{*}{ Salary } & SHO & .127 & .129 & .123 \\
K/9 & .118 & .072 & .241 \\
& WHIP & .071 & .067 & .143 \\
ERA & .067 & .116 & .134 \\
IP & .110 & .507 & .226 \\
\hline
\end{tabular}

TABLE 3: An analysis of the difference between actual and predicted performance of CPBL players.

\begin{tabular}{lccc}
\hline Data set & & Positions & \\
& Pitchers & Fielders & $35.1 \%$ \\
\hline Overall & $46.5 \%$ & $28.2 \%$ & $15.2 \%$ \\
4-year & $20.2 \%$ & $12.5 \%$ & $18.2 \%$ \\
3-year & $19.2 \%$ & $17.5 \%$ & $141.3 \%$ \\
2-year & $161.0 \%$ & $124.0 \%$ & All players \\
\hline
\end{tabular}

TABLE 4: Analysis summary of actual salary adjustment and actual and predicted performance gap.

\begin{tabular}{lcc}
\hline & $\begin{array}{c}\text { Actual } \\
\text { performance gap } \\
(-.062)\end{array}$ & $\begin{array}{c}\text { Predicted } \\
\text { performance } \\
\text { gap } \\
(.101)\end{array}$ \\
\hline Rate of salary adjustment $(.119)$ & $-.231^{*}$ & $.333^{*}$ \\
\hline
\end{tabular}

${ }^{*} p<.05$

\section{Discussion}

The following section will first discuss the results obtained and then propose recommendations to teams in the CBPL and future researchers. Finally, the limitation of this study will also be described.

4.1. Weightage of Criteria Affecting Player Salaries in the $C P B L$. The results obtained in this study showed that the salaries of players in the CBPL are affected by performance of previous and current seasons. This is in line with the suggestion by [6] to take into consideration past and present performance while evaluating the salaries of professional sportspersons. Furthermore, from Tables 1 and 2, it is clear that regardless of the players' position (pitchers or fielders) how the players perform in previous and current seasons has a significant effect on their current season's salaries $(0.493$ and 0.507). These results showed that teams in the CBPL do indeed take future performance prediction of their players into consideration when deciding their players' salaries for the new season.

4.2. Empirical Analysis: Salary Prediction for Players in the $C P B L$. Since teams in the CBPL refer to the players' past and future performance when appraising their salaries, the construction of an effective performance evaluation method is paramount. Therefore this study proposes the use of grey prediction model to forecast the players' performance for the coming season. The results of this study show that the proposed model provides better accuracy in predicting performance with a three- or four-year data sets (with error rate under 18.2\%). According to Ofori et al. [33], prediction model with such error rates has good forecasting abilities. However, when the players' historical data is only two years, the predictive error rate of the proposed model is as high as $141.3 \%$ which indicates bad forecasting abilities. In summary, for the proposed prediction model in this study to provide good forecast on the players' performance, the model requires at least a three-year data set. If the available data set is less than two years, this prediction model should not be used. In addition, these results also echoed the fact that new players coming into the Major League Baseball (MLB) are to be 
given a new fixed contract (pegged at US\$507,503 for 2016) and are only eligible for salary negotiation after three full years of playing in the league. This is the only avenue to protect MLB teams from spending too much money and making poor decisions on new unproven players. Furthermore, after analyzing the gap between players' predicted performance index and previous year's performance index together with the players' new annual salaries, this study found that there is a positive correlation between the abovementioned gap and players' salaries. This showed that the prediction model proposed in this study is able to reflect the actual pay raise (or cut) of players in the CBPL. However, the correlation between these two factors is not high; thus there is a need to take other factors, such as a player's popularity, how well he works with the team, and other personal preferences, into consideration while appraising the player's salary.

4.3. Conclusion. In world of professional sports, salary adjustments for players have always been an important topic for discussion. Summarizing the results above, this study has shown that teams in the CBPL do take future performance prediction of their players into consideration in addition to the players' past performance records when evaluating their salaries. Other than their technical performance on the pitch, teams may also include nontechnical factors. Teams must use at least three or more years of performance data in order to predict the players' future performance. This is to help decision-makers avoid making any wrong decision due to incomplete information. These findings also serve as a reminder to players to give their all during their practice sessions so that they may earn the trust of their coaches and a chance to play in actual games. Their great in-game performances will help them win accolades from fans and coaches which will then be reflected in the increase of their salaries.

4.4. Suggestions. How much an employee is paid is a reflection of his/her contribution to the organization, and the world of professional sports is no different. Teams in the CPBL should determine their players' salaries based on their in-game technical performances. Furthermore, due to insufficient data in forecasting future performances, teams could provide varied signing bonuses (due to different past performance records or future predicted performances) with a fixed salary package, just like the MLB. In doing so, team owners and/or managers can avoid depending on too many nonquantitative data or personal preferences while determining players' salaries which may affect the morale of the players and the team and consequently influence the business performance of their professional baseball teams. In recent years, teams in the CPBL have signed multiyear contracts with several of their players. This study did not take this scenario into consideration. Thus future researchers could conduct relevant follow-up studies on this multiyear contract scenario. Additionally, they may apply this concept to other professional baseball leagues in different regions or countries or to other professional sports of different kinds.

\section{Conflicts of Interest}

There are not any conflicts of interest concerning this paper.

\section{Acknowledgments}

This research is partially supported by the Ministry of Science and Technology, Taiwan, under Grant no. MOST 104-2410H-156-013.

\section{References}

[1] A. Bryson, B. Buraimo, and R. Simmons, "Do salaries improve worker performance?” Labour Economics, vol. 18, no. 4, pp. 424433, 2011.

[2] B. L. Rau and D. Feinauer, "The role of internal agents in starting salary negotiations," Human Resource Management Review, vol. 16, no. 1, pp. 47-66, 2006.

[3] N. Scelles, B. Helleu, C. Durand, and L. Bonnal, "Determinants of professional sports firm values in the united states and europe: A comparison between sports over the period 20042011," International Journal of Sport Finance, vol. 8, no. 4, pp. 280-293, 2013.

[4] K. W. Einolf, "Is winning everything?: A data envelopment analysis of major league baseball and the national football league," Journal of Sports Economics, vol. 5, no. 2, pp. 127-151, 2004.

[5] W. N. Kinnard Jr., M. B. Geckler, and J. W. Delottie, "Team performance, attendance and risk for major league baseball stadiums: 1970-1994," Real Estate Issues, vol. 22, pp. 72-80, 1997.

[6] J. K. Hakes and R. D. Sauer, "An economic evaluation of the moneyball hypothesis," Journal of Economic Perspectives, vol. 20, no. 3, pp. 173-185, 2006.

[7] D. J. Berri, S. L. Brook, and M. B. Schmidt, "Does one simply need to score to score," International Journal of Sports Finance, vol. 2, pp. 190-205, 2007.

[8] L. Bodin and E. Epstein, "Who's on first-with probability 0.4," Computers \& Operations Research, vol. 27, no. 3, pp. 205-215, 2000.

[9] J. K. Hakes and R. D. Sauer, "The moneyball anomaly and payroll efficiency: a further investigation," International Journal of Sport Finance, vol. 2, pp. 177-189, 2007.

[10] D. J. Berri and M. B. Schmidt, "On the evaluation of kickers in the national football league," International Journal of Sport Finance, vol. 8, no. 4, pp. 263-278, 2013.

[11] C. N. Annala and J. Winfree, "Salary distribution and team performance in major league baseball," Sport Management Review, vol. 14, no. 2, pp. 167-175, 2011.

[12] W.-J. Jane, "Raising salary or redistributing it: A panel analysis of major league baseball," Economics Letters, vol. 107, no. 2, pp. 297-299, 2010.

[13] M. Mondello and J. Maxcy, "The impact of salary dispersion and performance bonuses in NFL organizations," Management Decision, vol. 47, no. 1, pp. 110-123, 2009.

[14] R. E. McCormick and R. D. Tollison, "Why do black basketball players work more for less money?" Journal of Economic Behavior \& Organization, vol. 44, no. 2, pp. 201-219, 2001.

[15] T. Sueyoshi, K. Ohnishi, and Y. Kinase, "Benchmark approach for baseball evaluation," European Journal of Operational Research, vol. 115, no. 3, pp. 429-448, 1999. 
[16] D. J. Slottje, J. G. Hirschberg, K. J. Hayes, and G. W. Scully, "A new method for detecting individual and group labor market discrimination," Journal of Econometrics, vol. 61, no. 1, pp. 4364, 1994.

[17] R. D. Baker and I. G. McHale, "Forecasting exact scores in national football league games," International Journal of Forecasting, vol. 29, no. 1, pp. 122-130, 2013.

[18] B. L. Boulier and O. SH, "Predicting the outcomes of national football league games," International Journal of Forecasting, vol. 19, no. 2, pp. 257-270, 2003.

[19] W. J. Knottenbelt, D. Spanias, and A. M. Madurska, "A commonopponent stochastic model for predicting the outcome of professional tennis matches," Computers \& Mathematics with Applications. An International Journal, vol. 64, no. 12, pp. 38203827, 2012.

[20] B. Min, J. Kim, C. Choe, H. Eom, and R. I. (Bob) McKay, "A compound framework for sports results prediction: A football case study," Knowledge-Based Systems, vol. 21, no. 7, pp. 551-562, 2008.

[21] M. Xia and W. K. Wong, "A seasonal discrete grey forecasting model for fashion retailing," Knowledge-Based Systems, vol. 57, pp. 119-126, 2014.

[22] T. M. Choi, C. L. Hui, N. Liu, S. F. Ng, and Y. Yu, "Fast fashion sales forecasting with limited data and time," Decision Support Systems, vol. 59, pp. 84-92, 2014.

[23] C.-S. Lin, "Forecasting and analyzing the competitive diffusion of mobile cellular broadband and fixed broadband in Taiwan with limited historical data," Economic Modelling, vol. 35, pp. 207-213, 2013.

[24] R. B. C. Benítez, R. B. C. Paredes, G. Lodewijks, and J. L. Nabais, "Damp trend Grey Model forecasting method for airline industry," Expert Systems with Applications, vol. 40, no. 12, pp. 4915-4921, 2013.

[25] C.-I. Hsu and Y.-H. Wen, "Improved grey prediction models for the trans-pacific air passenger market," Transportation Planning and Technology, vol. 22, no. 2, pp. 87-107, 1998.

[26] X. Liu, H. Peng, Y. Bai, Y. Zhu, and L. Liao, "Tourism Flows Prediction based on an Improved Grey GM(1,1) Model," Procedia Social and Behavioral Sciences, vol. 138, pp. 767-775, 2014.

[27] C. Hsu and C. Chen, "Applications of improved grey prediction model for power demand forecasting," Energy Conversion and Management, vol. 44, no. 14, pp. 2241-2249, 2003.

[28] L.-C. Hsu, "Applying the Grey prediction model to the global integrated circuit industry," Technological Forecasting \& Social Change, vol. 70, no. 6, pp. 563-574, 2003.

[29] T. H. M. El-Fouly, E. F. El-Saadany, and M. M. A. Salama, "Grey predictor for wind energy conversion systems output power prediction," IEEE Transactions on Power Systems, vol. 21, no. 3, pp. 1450-1452, 2006.

[30] W. Zhou and J.-M. He, "Generalized GM $(1,1)$ model and its application in forecasting of fuel production," Applied Mathematical Modelling, vol. 37, no. 9, pp. 6234-6243, 2013.

[31] M. Lewis, Moneyball, The Art of Winning an Unfair Game, Norton, Ny, USA, 2003.

[32] J. L. Deng, "Introduction to grey system theory," The Journal of Grey System, vol. 1, no. 1, pp. 1-24, 1989.

[33] T. Ofori, L. Ephraim, and F. Nyarko, "Mathematical model of ghanas population growth," International Journal of Modern Management Sciences, vol. 2, pp. 57-66, 2013.

[34] C.-C. Chen, Y.-T. Lee, and C.-M. Tsai, "Professional baseball team starting pitcher selection using AHP and topsis methods,"
International Journal of Performance Analysis in Sport, vol. 14, no. 2, pp. 545-563, 2014.

[35] C. C. Chuang, T. T. Chen, and C. C. Chen, "Analyzing the edge of professional Taiwanese baseball league starting pitchers using the Entropy and TOPSIS method," Journal of Physical Education and Sport Management, vol. 6, pp. 1-18, 2015.

[36] C. D. Lewis, Industrial and business forecasting methods: A practical guide to exponential smoothing and curve fitting, Butterworth-Heinemann, Oxford, UK, 1982. 


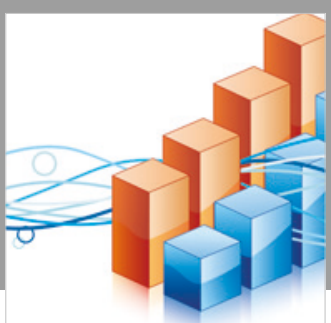

Advances in

Operations Research

\section{-n-m}
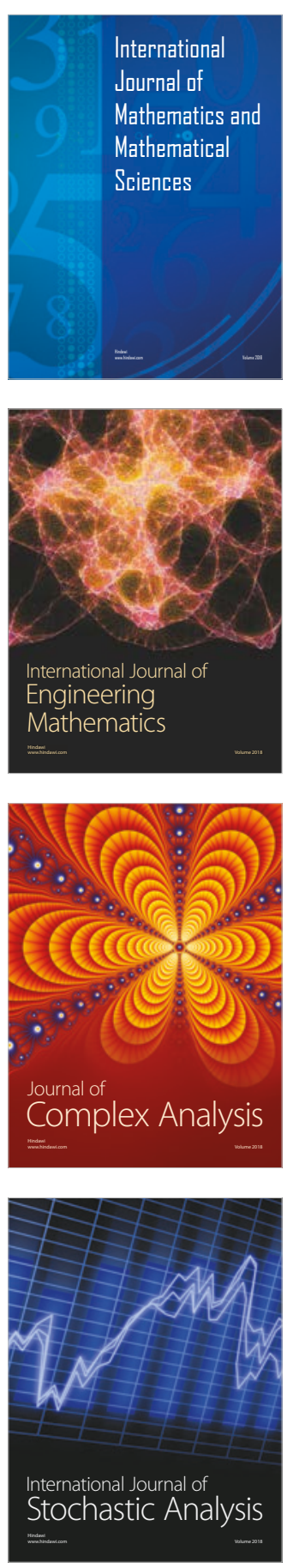
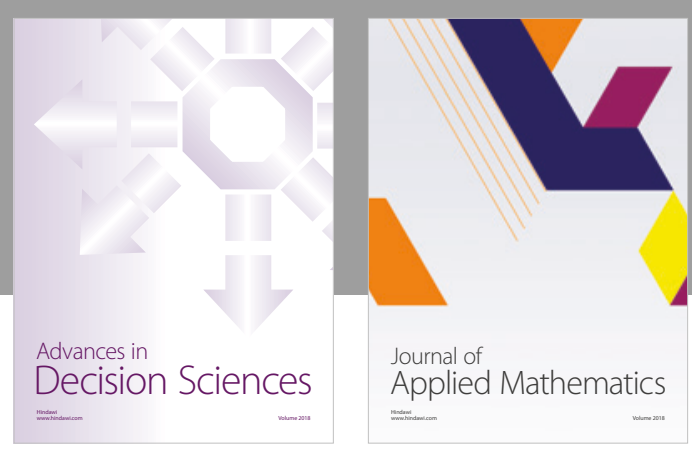

Journal of

Applied Mathematics
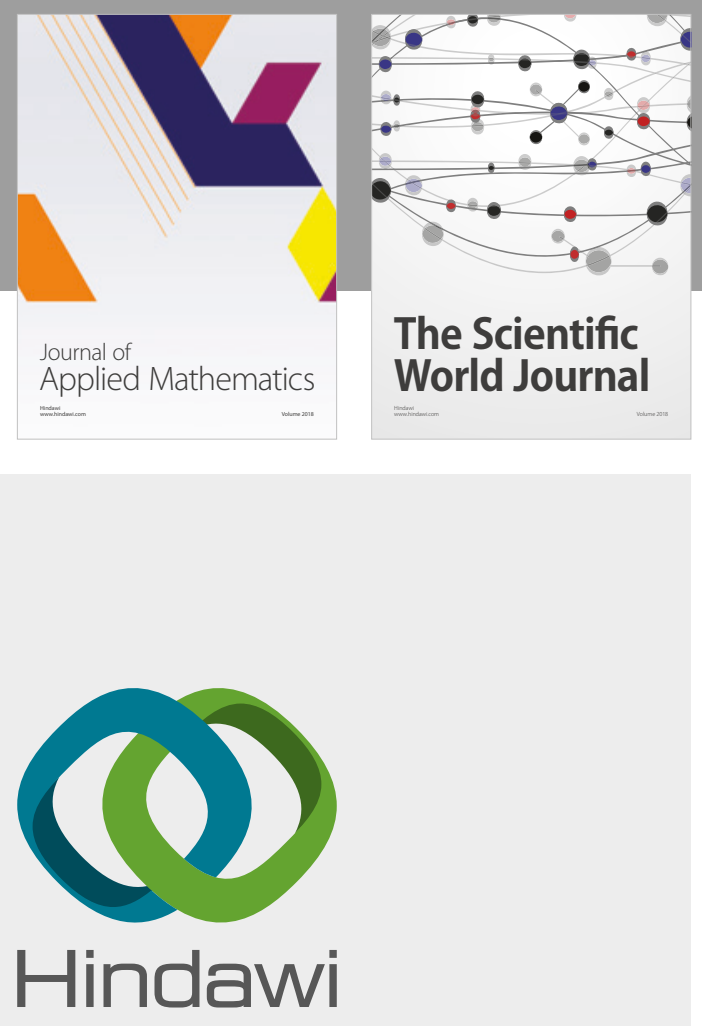

Submit your manuscripts at

www.hindawi.com

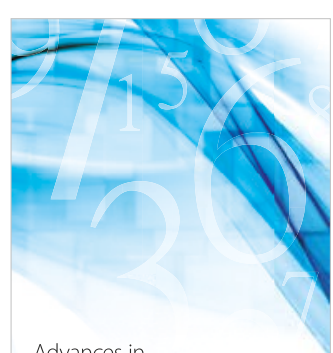

Advances in
Numerical Analysis
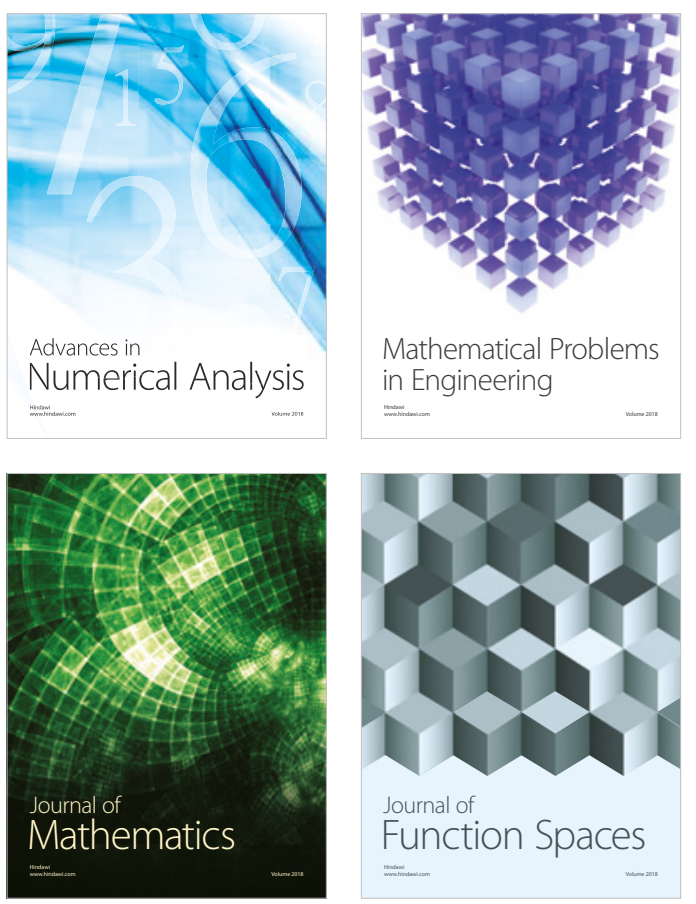

Mathematical Problems in Engineering

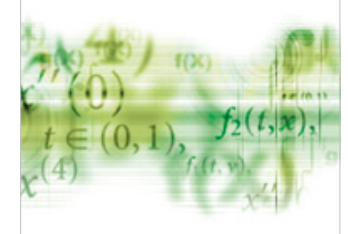

International Journal of

Differential Equations

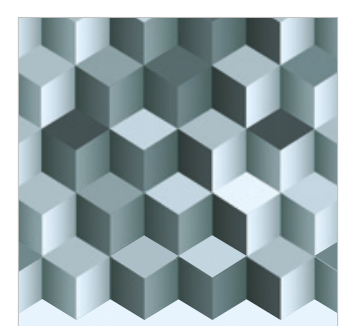

Journal of

Function Spaces

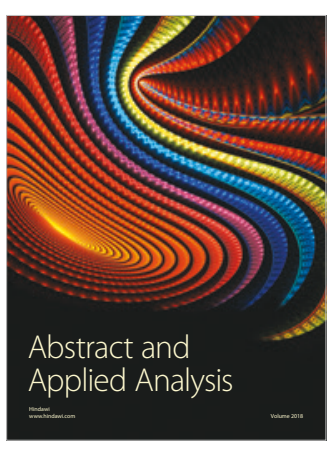

The Scientific

World Journal

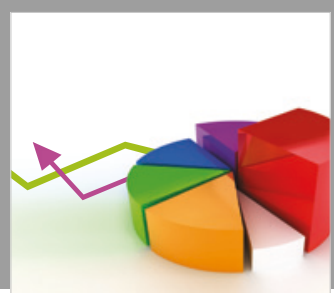

Journal of

Probability and Statistics
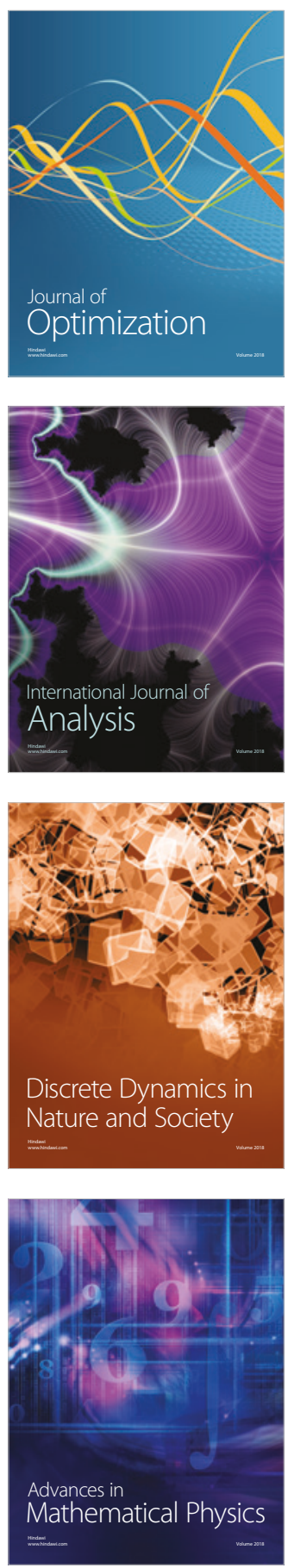